$\mathbb{P}$ periodica polytechnica

Mechanical Engineering

$54 / 2(2010) 8388$

doi: 10.3311/pp.me.2010-2.04

web: http://www.pp.bme.hu/me

(c) Periodica Polytechnica 2010

RESEARCH ARTICLE

\section{Effect of leaser treatment on the surface of cast iron cylinder bores}

\author{
Kornél Májlinger / Péter J. Szabó
}

Received 2010-11-31

\begin{abstract}
The environmental and pollution materials emission standards in Europe are going to be more strict. In order to meet the standards, a European automotive manufacturer performs a finishing laser treatment on the honed cast iron cylinder bores of their V-engine blocks. Samples of laser treated cast iron cylinder bores with lamellar graphite were investigated. Due to the growing popularity and high efficiency of fiber lasers, samples treated with $\mathrm{Yb}$-fiber lasers were investigated. In order to evaluate the microstructure and grain size of the laser treated layer, scanning electron microscopic images were taken on cross sectioned samples with a scanning electron microscopelfocused ion beam dual beam electron microscope. The samples were found to be ultra fine grained. Nanoindentation hardness measurements of the surface layer showed a clear linear trend between the laser power density in the applied range and the measured hardness. Additional micro hardness measurements suggest an annealed region beneath the surface.
\end{abstract}

\section{Keywords}

laser surface treatment $\cdot$ cast iron $\cdot$ cylinder bore $\cdot$ focused ion beam $\cdot$ nanoindentation

\section{Acknowledgement}

This work is connected to the scientific program of the "Development of quality-oriented and harmonized $R+D+I$ strategy and functional model at BME project. This project is supported by the New Hungary Development Plan (Project ID: TÁMOP4.2.1/B-09/1/KMR-2010-0002). This paper was supported by the János Bolyai Research Scholarship of the Hungarian Academy of Sciences.

\section{Kornél Májlinger}

Budapest University of Technology and Economics,Department of Material Science and Engineering,, Bertalan Lajos street 7, H-1111 Budapest, Hungary e-mail: pmgpwo@hotmail.com

\section{Péter J. Szabó}

Budapest University of Technology and Economics,Department of Material Science and Engineering,, Bertalan Lajos street 7, H-1111 Budapest, Hungary e-mail: szpj@eik.bme.hu

\section{Introduction}

The environmental and pollution materials emission standards in Europe and worldwide are going to be more strict, and fuel prices are continuously increasing. These facts persuade the automotive engine developers to build more efficient and environmentally friendly engines. To meet environmental regulations and because of increasing fuel prices, it is expected that, even at higher engine power, the fuel and oil consumption should not increase. It is also obvious that the engines should have a long lifetime [1]. Both the consumption reduction and the power increase of Otto- or Diesel-engines cause higher pressures in the combustion chamber resulting higher tribological load and wear rate for the piston rings and to the cylinder bore [1]. Laser treatments are widely used for surface modifications, from surface alloying to surface shock hardening [2, $[5]$ to improve surface properties of sliding machine parts. Thus, laser surface treatments gain an increasing significance in the automotive industry. A wide range of automotive parts, from brake drums to engine parts [6-10], are laser treated to alter the surface and near surface properties of the materials. To improve the mechanical and tribological properties of different cylinder bores it is possible to use special mechanical treatment [11] or chemical coatings [12,14] and laser structuring treatments [15] or - which is used by a large European automotive manufacturer - a special laser surface treatment on the cast iron V-block engines to alter the properties of the cylinder bores. Due to the laser treatment, the area near the surface of the cylinder bore becomes harder and more wear resistant. Furthermore, due to the inhomogenity of the pearlitic matrix and carbon lamellae, oil reserving holes are formed. This treatment results in an increased power output and reduced oil consumption [1, 16].

\section{Materials and methods}

\subsection{Leaser treatment}

The goal of the laser treatment is to melt a thin layer of the surface. At the same time, the laser induced plasma over the surface evaporates the graphite lamellae, deeper than the metallic surface itself. So these "holes" are practically noncommunicating oil reservoirs [1]. This treatment is patented, the 
patent number is: EP 1738859 A1. Recently, the cylinder bores in the mass-production are treated with a $\mathrm{Xe}-\mathrm{Cl}$ excimer laser which works in the UV wavelength region (308 nm). During treatment the workpiece is treated with a rectangular laserspot with 4 times overlap in a definite raster. The adjustable parameters during the laser treatment are: the scale of the overlap (scanning grid), the mean laser energy density on the surface and the speed of the scanning. There are further experiments to find alternative laser sources, because the excimer lasers have high maintenance requirements and the maintenance and servicing costs are higher than those of the solid state lasers. A further disadvantage of the currently applied excimer laser is that, because of the geometry of the optical output system during laser treatment, the whole cylinder block has to be rotated around the laser output window which significantly reduces the efficiency of the laser system. Furthermore, excimer lasers have large space requirements. The material of the samples was grey cast iron with lamellar graphite and pearlitic microstructure (GJL-250). After the hone process and the final laser treatment, the samples were cut out from the cast iron engine blocks. In order to replace the excimer laser, four samples treated with an IPG Yb-fiber laser source with different laser energy densities were investigated. The samples were treated with two times overlap during the insertion as well as during removal (four time overlap) of the laser output tube. The spot form was a $0.9 \times 0.9 \mathrm{~mm}$ rectangle. The main laser parameters for the laser treatment are shown in Tab. 1 . The slight difference between the two series Y1-Y4 and Y5-Y8 is that the Y1-Y4 laser treatments were made in the same bore of the cylinder block and the Y5-Y8 laser treatments were made in the same engine block but in separate cylinder bores.

\subsection{Experimental}

\subsubsection{Focused Ion Beam investigation}

The focused ion beam (FIB) investigations were made by a LEO Gemini cross beam scanning electron microscope (SEM), SEM/FIB scanning electron microscope. Images were taken from regions at least $10 \mu \mathrm{m}$ away from the graphite lamellaes to avoid their influence. In earlier works [17-19], half of a regular cross section for TEM lamellae cutout were made with the ion beam and then images were taken, with lowered ion current, of the wall of the obtained cavity. This process was simplified, by making the FIB cut on the edge of a polished bulk samples. The protective Pt layer was also left from the surface. The main parameters for FIB machining and imaging are displayed in Tab.2.

Due to the difficulties with the sample, the ion beam current during coarse cutting was $2 \mathrm{nA}$. The angle between the measured surface and the ion beam during imaging was $54^{\circ}$. To determine the average grain size and layer thickness, several FIB images were merged together to cover an area of approximately $20 \times 7 \mu \mathrm{m}(20 \mu \mathrm{m}$ in horizontal and $7 \mu \mathrm{m}$ in vertical direction). The average grain size was determined along 3 lines ( 3 horizontal lines were drawn into the laser treated layer, from grain boundary to grain boundary, and the number of the grains along these lines with known length were counted). Additional images from the laser treated surface were taken by a Philips XL 30 SEM.

\subsubsection{Nanoindentation measurement}

To determine the hardness of the laser treated layer, nanoindentation measurements were performed with an UMIS nanoindenter equipped with a Vickers pyramid. Four hundred measurement points were made, with $5 \mathrm{mN}$ load, within a $20 \times 20$ raster, with $20 \mu \mathrm{m}$ distance between indentations. The acceptable load vs. indentation curves were selected by different criteria (like maximal indentations depth $200 \mathrm{~nm}$ and null point error $<10$ $\mathrm{nm})$ to avoid false hardness values. Only the hardness values of the good measurement points were evaluated. A frequency count was calculated and displayed in a histogram, then different curves were fitted to the diagram. The lognormal curve was found to fit the best for the hardness values (see Fig. 1)

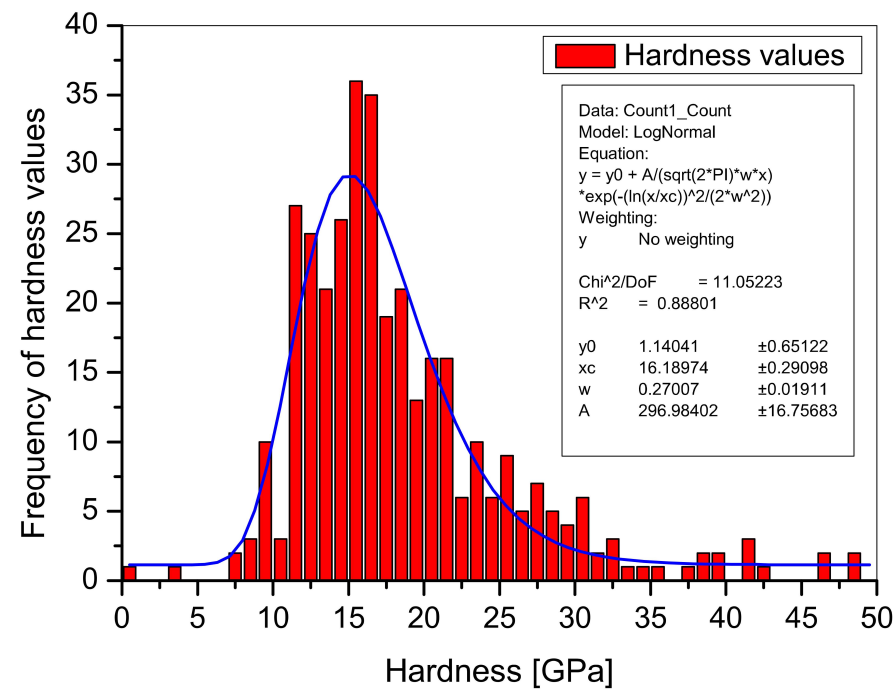

Fig. 1. Histogram of the nanoindentation hardness values of sample $d$ and the fitted lognormal curve.

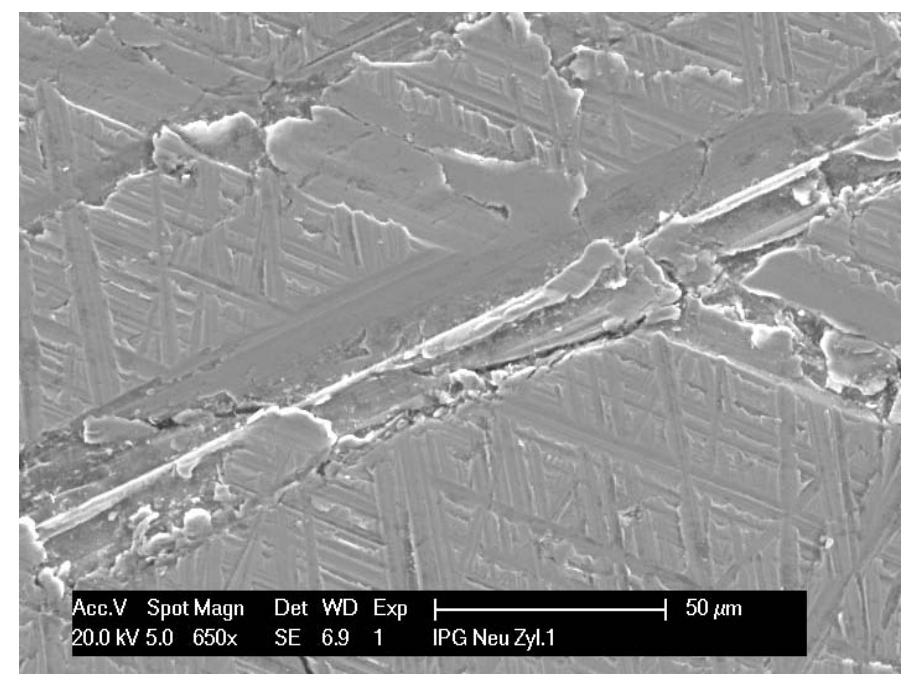

Fig. 2. SEM image of the honed surface.

The hardness of the base material was also determined. To avoid the effect of the top layer of the surface, which had been 
Tab. 1. The main laser parameters for the laser treatment with $\mathrm{Yb}$-fiberlaser

\begin{tabular}{llllll}
\hline Sample & $\begin{array}{l}\text { Wavelength } \\
(\mathrm{nm})\end{array}$ & $\begin{array}{l}\text { Pulselength } \\
(\mathrm{ns})\end{array}$ & $\begin{array}{l}\text { Pulse } \\
\text { quency }(\mathrm{Hz})\end{array}$ & $\begin{array}{l}\text { fre- } \\
\left(\mathrm{mJ} / \mathrm{mm}^{2}\right)\end{array}$ & $\begin{array}{l}\text { Power density } \\
\left(\mathrm{mJ} /\left(\mathrm{mm}^{2} \mathrm{~ns}\right)\right)\end{array}$ \\
\hline $\mathrm{Y} 1$ & 1065 & 140 & 12500 & 15.8 & 0.1129 \\
$\mathrm{Y} 2$ & 1065 & 140 & 12500 & 19.8 & 0.1411 \\
$\mathrm{Y} 3$ & 1065 & 140 & 12500 & 24.7 & 0.1764 \\
$\mathrm{Y} 4$ & 1065 & 140 & 12500 & 29.6 & 0.2116 \\
$\mathrm{Y} 5$ & 1065 & 140 & 12500 & 19.2 & 0.1369 \\
$\mathrm{Y} 6$ & 1065 & 140 & 12500 & 22.6 & 0.1616 \\
$\mathrm{Y} 7$ & 1065 & 140 & 12500 & 26.7 & 0.1905 \\
$\mathrm{Y} 8$ & 1065 & 140 & 12500 & 30.4 & 0.2173 \\
\hline
\end{tabular}

Tab. 2. The main parameters for FIB machining and imaging

\begin{tabular}{lll}
\hline FIB operation & lon beam voltage & Ion beam current \\
\hline Coarse cut & $30 \mathrm{kV}$ & $1 \mathrm{nA}$ \\
Fine cut & $30 \mathrm{kV}$ & $200 \mathrm{pA}$ \\
lon beam etching & $30 \mathrm{kV}$ & $50 \mathrm{pA}$ \\
lon beam imaging & $30 \mathrm{kV}$ & $20 \mathrm{pA}$ \\
\hline
\end{tabular}

Tab. 3. The molten layer depths measured on FIB and SEM images and grain size measured on FIB images.

\begin{tabular}{llll}
\hline Sample & $\begin{array}{l}\text { Molten layer depth } \\
\mathrm{R}_{\text {FIB }}(\mu \mathrm{m})\end{array}$ & $\begin{array}{l}\text { Grain size } \\
\mathrm{R}_{\text {SEM }}(\mu \mathrm{m})\end{array}$ & $\mathrm{d}_{\text {FIB }}(\mathrm{nm})$ \\
\hline Y1 & n. a. & $0.50-1.14$ & n. a. \\
Y2 & n. a. & $0.51-1.01$ & n. a. \\
Y3 & n. a. & $0.52-1.83$ & n. a. \\
Y4 & n. a. & $0.55-1.67$ & n. a. \\
Y5 & $0.90-1.04$ & $0.52-1.35$ & 243 \\
Y6 & $0.51-0.81$ & $0.55-2.07$ & 151 \\
Y7 & $0.73-0.97$ & $0.56-1.57$ & 214 \\
Y8 & $0.93-1.13$ & $0.76-2.11$ & 204 \\
\hline
\end{tabular}

previously mechanically deformed, it was prepared similarly to a sample for electron backscattered diffraction (EBSD) measurement. The sample was embedded in metallographic mold resign, prepared like a normal metallographic sample [20], and after polishing by $1 \mu \mathrm{m}$ grain sized $\mathrm{Al}_{2} \mathrm{O}_{3}$ suspension it was etched for $10 \mathrm{sec}$ with $2 \%$ nital etchant. Afterwards, the sample was further polished with an automatic polishing machine, by a $0.05 \mu \mathrm{m}$ grain sized $\mathrm{SiO}_{2}$ suspension, with $5 \mathrm{~N}$ force, for 35 minutes.

\subsubsection{Microhardness measurements}

The microhardness measurements were carried out by a Buehler 1011 microhardness tester with a Vickers pyramid. The applied loads were 1000, 500, 300, 200, 100, 50, 25 and 10 grams. For every load, at least 15 measurements were made and the Gaussian mean values were determined (like described above). The measurement points were selected far away from the graphite lamellaes in order to avoid their influence. To measure the imprints obtained by $10 \mathrm{~g}$ load, an SEM was used.

\section{Results and discussion}

\subsection{Focused lon Beam investigation}

In FIB cross section images (Fig. 3), it is well seen that the laser treatment caused the top of the surface to melt. As it was mentioned previously, sample Y5 (Fig. 3) was cut in the first step with $2 \mathrm{nA}$ ion beam current, which caused a visible curtaining effect [21,22] that could not have been removed by the fine cut step. To obtain fine surface quality, it is necessary by this cast iron to reduce the current by the coarse cut step, to further processing we applied. The thickness of the laser treated layers on the FIB images $\left(\mathrm{R}_{\mathrm{FIB}}\right)$ was determined by an image analysing software. The thickness values were measured also by SEM $\left(\mathrm{R}_{\mathrm{SEM}}\right)$ on cross section samples prepared by a conventional mechanical method [20]. The molten layer thicknesses are displayed in Table. 3. As it can be seen the layer thickness widely varies with the place of measurement (between 0.5-2.1 $\mu \mathrm{m}$ ), because of the wavy surface after honing. However, with the exception of some regions, it can be said that the thickness of the top layer after laser treatment is cca. $1 \mu \mathrm{m}$. The average grain sizes $\left(\mathrm{d}_{\mathrm{FIB}}\right)$ measured on FIB images with the Image Pro Plus program are also listed in Tab. 3. All of the sam- 

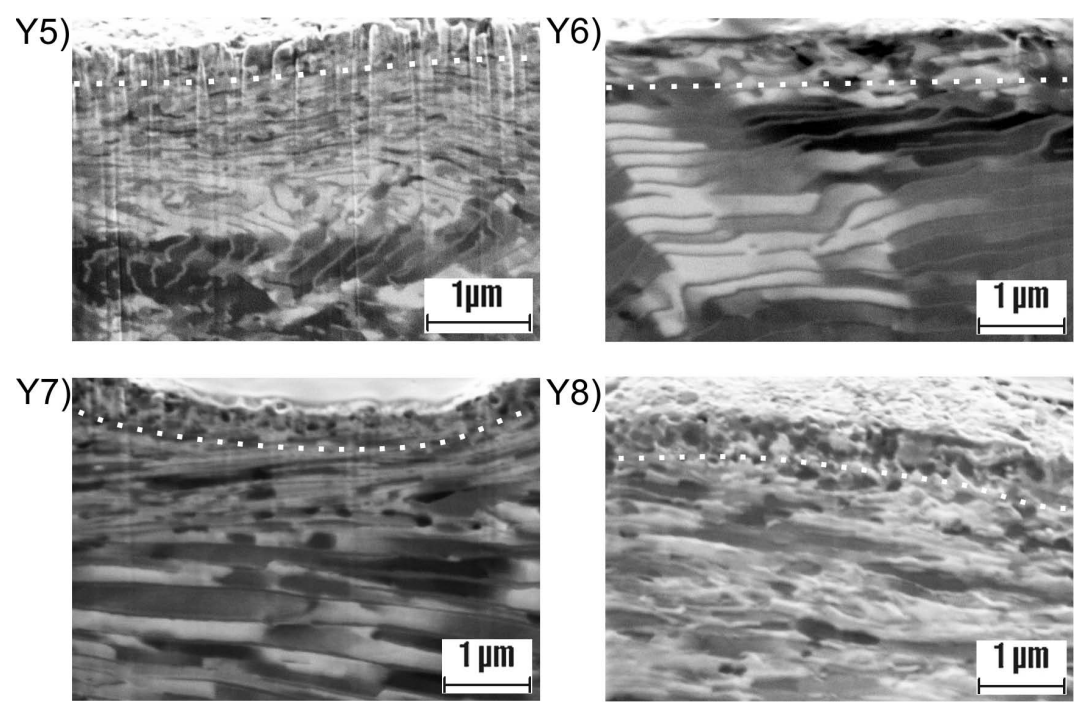

Fig. 3. FIB cross section images of the cylinder bores. The laser treated surspectively. face can be seen above the dotted line for samples Y5), Y6), Y7) and Y8) re-
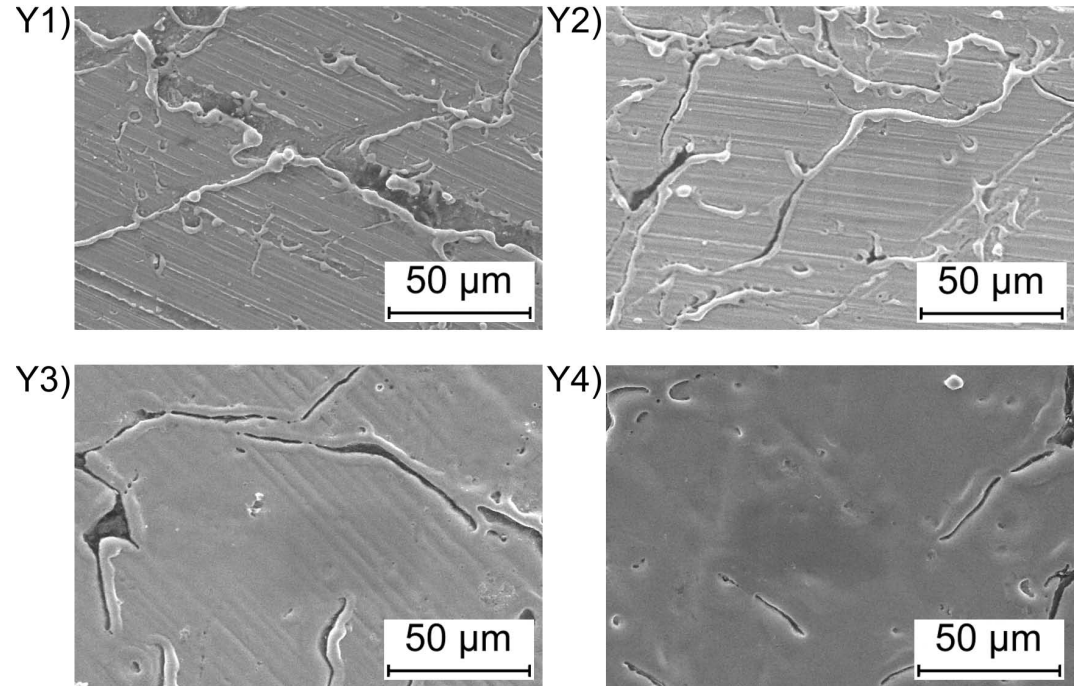

Fig. 4. SEM images of the laser treated surfaces for samples Y1), Y2), Y3) and Y4) respectively.
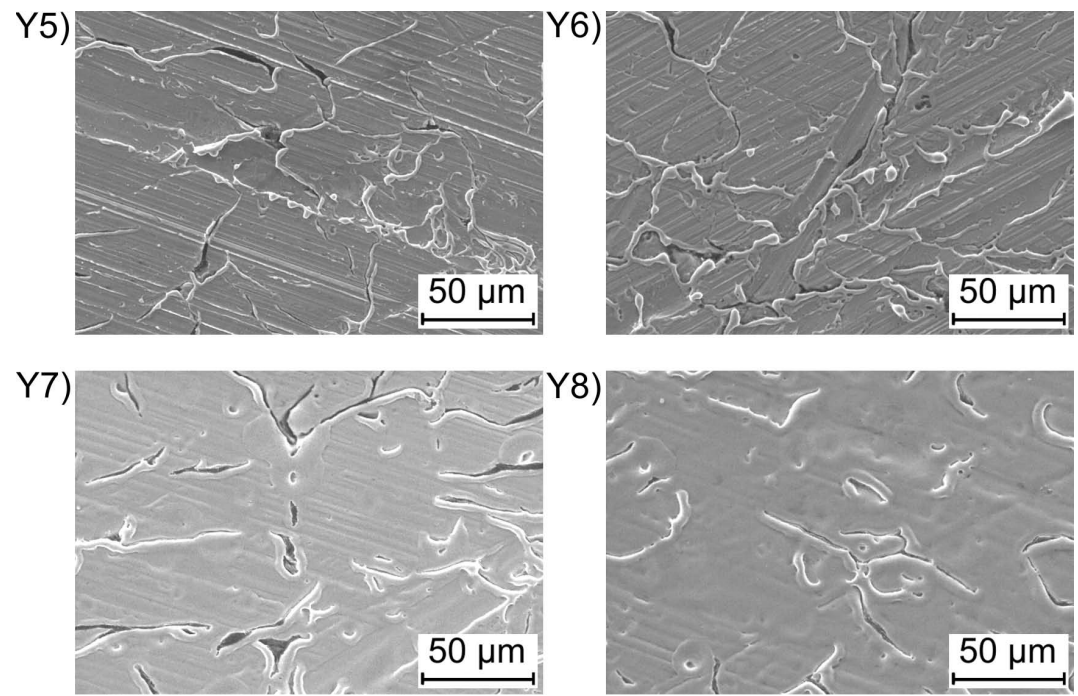

Fig. 5. SEM images of the laser treated surfaces for samples $Y$ 5), Y6),Y7) and Y8) respectively.

ples were found to have ultra fine grained structure with grain sizes between 150-240 $\mathrm{nm}$. The ultra-fine grained structure was most likely formed due to the rapid cooling caused by the large heat gradient during solidification of the molten surface. It is well known that during solidification, the critical core size is 
inversely proportional to the undercooling:

$$
r=\frac{2 \gamma T_{\mathrm{E}}}{L \Delta T}
$$

where $r$ is the critical core radius, $\gamma$ is the surface energy of the core, $T_{E}$ is the equilibrium temperature (the melting point), $L$ is the latent heat during solidification, and $T$ is the undercooling. Here, the undercooling is very high due to the small molten volume and the high volume of surrounding cold bulk. Therefore, the critical core radius is small, which means that several cores are formed in the same time and thus the final grain size is very small.

Below this layer, the base material has many larger grains. These grains are slightly curved in one direction due to the mechanical machining of the cylinder bores. Surface morphology highly influences the sliding behavior of friction parts. In order to investigate this morphology, SEM images were taken from the laser treated surfaces. First SEM images were taken from the honed surface (Fig. 2). There are honing marks/scretches with different width and depth on the surface after the hone process. This schratches form a communicating channel system, where the oil can escape along the piston ring during the operation of the engine. The laser treatment smoothens this surface (Fig. 4), (Fig. 5) and in the outburned graphite holes a non communicative oil reserving system is formed, which provides good sliding properties and reduced oil consumption. As it can be seen in the low magnification SEM images (Fig. 4. Fig. 5, the surfaces of sample Y1, Y2 and Y5, Y6 are not uniformly molten: the metal layer above the graphite lamellaes are molten and are kept together by the graphite lamellaes. The marks of the hone process and the wavy surface are still noticeable. This is unwanted during the operation of the engine, and failure can result from friction by the piston rings in the engine. The samples Y4, Y5 and Y7, Y8 treated with more laser energy show much smother surfaces, which are applicable for the operation of the motor. For further investigation of the surface properties nanoindentation measurements were performed.

\subsection{Nanoindentation measurement}

As displayed in Fig. 6, a considerable hardness increment of the surface took place after the mechanical hone process and also after laser treatment.In the case of a honed surface, the top layer of the surface is heavily deformed, due to the effect of mechanical machining. During laser pulses, plasma is formed over the surface, which only allows the top layer of the cast iron surface to melt. The hardness increment shows a clear linear connection with the increasing laser power density in the investigated regimes. In case of samples Y1-Y4 (from the same bore), a much better correlations coefficient of the linear fitting was observed than in case of samples Y5-Y6 (different bores) due to the less inhomogenity of the cast iron base material within a single cylinder bore than the whole engine block. This hardness increment of the surface layer is caused most likely by the ultra fine grained structure and high dislocation densities on the surface after the laser pulse. To achieve a higher hardness than that of the honed surface, a laser energy density higher than about $0.16-0.185 \mathrm{~mJ} /\left(\mathrm{mm}^{2} \mathrm{~ns}\right)$ is needed. In order to investigate if the laser treatment had any effect in deeper layers in the surface, microhardness measurements were made with increasing load levels.

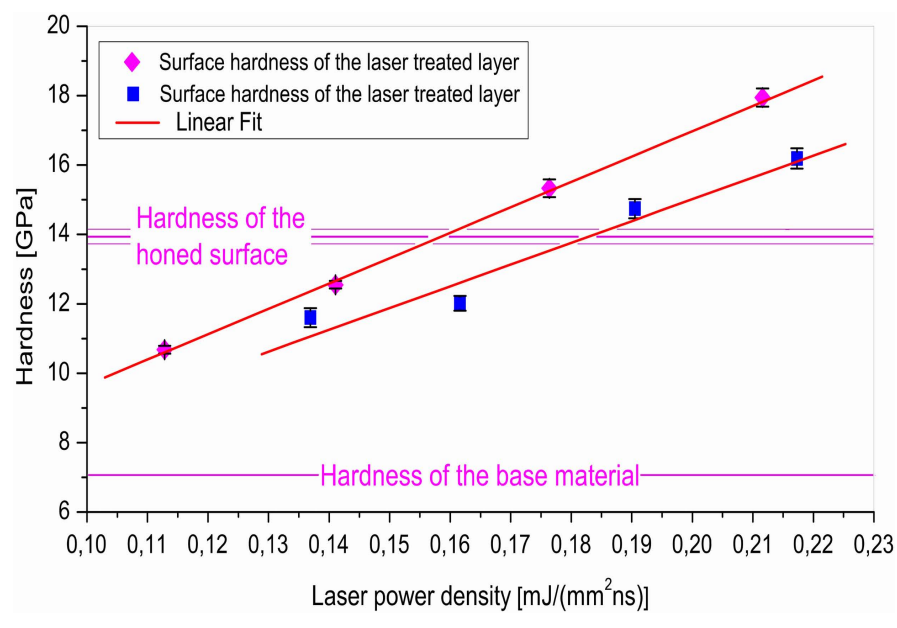

Fig. 6. Hardness values of the laser treated surfaces, the base material and the honed surface measured by nanoindenter. are the Y1-Y4 samples the square of the correlations coefficient of the linear fitting is $\mathrm{R}^{2}=0.998$, are the Y5-Y8 samples, the square of the correlations coefficient of the linear fitting is $\mathrm{R}^{2}=0.935$

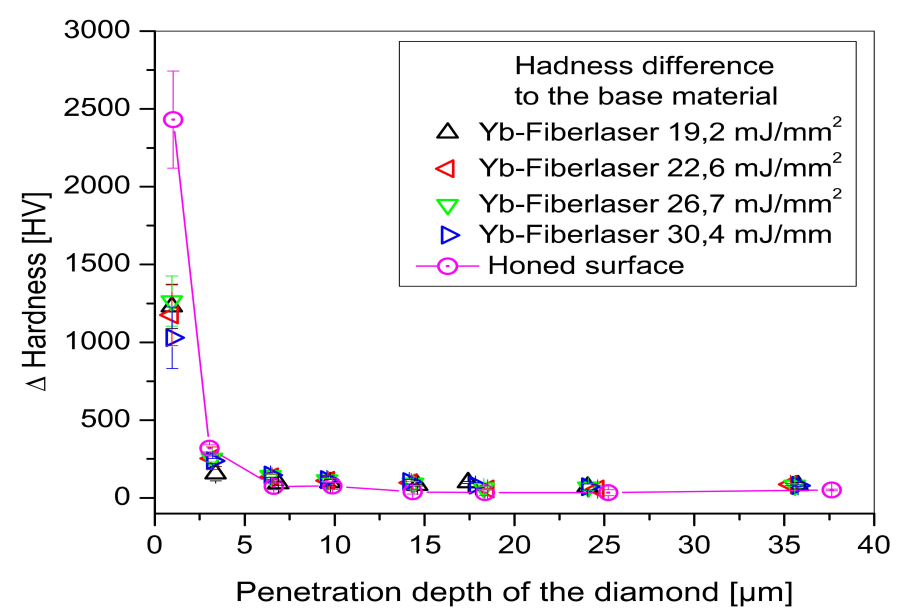

Fig. 7. Microvickers hardness values of the Y5-Y8 laser treated and the honed surface measured at different loads and the hardness values of the base material are subtracted.

\subsection{Microhardness measurement}

The microhardness values are displayed in Fig. 7 and Fig. 8 The penetration depths of the diamond tip were calculated from the Vickers hardness formulae and displayed in these figures. First the hardness values of the base material at different loads were substracted from the values of the laser treated surfaces in Fig. 7)All the samples showed increasing hardness compared to the base material, especially in the $1-3 \mu \mathrm{m}$ penetration range. The honed specimens were found to be softer than the laser treated ones, above ca. $6 \mu \mathrm{m}$ depth. However, at smaller inden- 


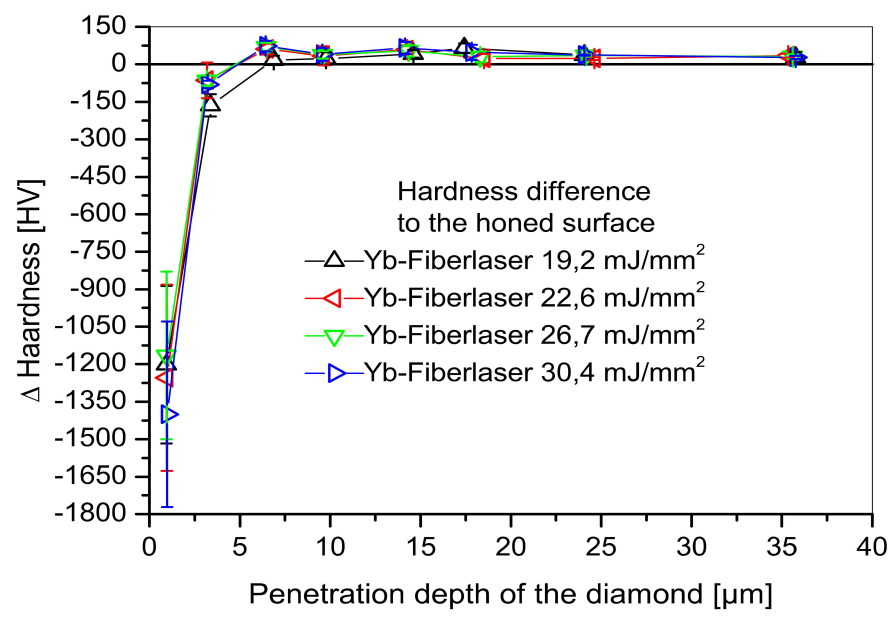

Fig. 8. Mickrovickers hardness values of the Y5-Y8 laser treated surface measured at different loads where the hardness values of the honed surface are subtracted.

tation depths, it was the hardest. This was caused by the high deformation rate and dislocation density in the top 1-3 $\mu$ m layer of the surface. The hardness values of the laser treated samples were identical, within the standard deviation. The hardness values of the honed surface and the laser treated samples were compared in Fig. 8 where the hardness values of the honed surface were subtracted from the laser treated ones. Due to the laser treatment, a softer layer was formed beneath the outermost surface. This should be due to the annealing effect under the molten zone, reducing the dislocation density by the laser remelting. These two layers together caused an overall softening until the penetration depth reached ca. $6 \mu \mathrm{m}$. The sample treated with the largest energy was the softest in the top region, where the thickest annealed zone could exist.

\subsection{Conclusion}

From the results of the above mentioned and discussed FIB and hardness measurements, the following conclusions can be drawn: Due to the laser treatment of the honed surface of pearlitic cast iron with graphite lamellaes in the $0.1129-0.2116$ and $0.1369-0.2173 \mathrm{~mJ} /\left(\mathrm{mm}^{2} \mathrm{~ns}\right)$ laser power density range, the top 1-2 $\mu \mathrm{m}$ melts and an ultra fine grained structure was formed. Considerable hardness increments, compared to the base material, was observed by nanoindentation measurements which increased in this range linearly. However, microhardness measurements showed softening. Since the penetration depth of microhardness measurement is much larger than that of nanoindentation, this suggests the existence of an annealed volume beneath the top molten layer of the surface.

\section{References}

1 Lindner $\mathbf{H}$, Bergmann $\mathbf{H}$ W, Brandenstein C, Lang A, Queitsch $\mathbf{R}$, Reichstein $\mathbf{S}$, Stengel E, UV-Laserbelichtung von GraugubZylinderlaufbahnen von Verbrennungskraftmaschinen, VDI-Berichte, 1764, (2003), 73-96.

2 Migliore L, Laser Materials Processing, (1996).
3 Webb C E, Handbook of Laser Technology and Applications, third vol, IOP Publishing, Philadelphia, 2004.

4 Ion J C, Laser Processing of Engineering Materials, Elsevier, Oxford, 2005.

5 Ready J F, LIA Handbook of Laser Materials Processing, Laser Institute of America, Orlando, 2011.

6 Liu X B, Yu G, Guo J, Shang Q Y, Zhang Z G, Gu Y J, Analysis of laser surface hardened layers of automobile engine cylinder liner, J. of Iron and Steel Res, 14, (2007), 42-46.

7 Damborenea J, Surface modification of metals by high power lasers, Surf. and Coat. Tech, 100-101, (1998), 377-382.

8 Duffet G, Sallamand P, Vannes A B, Improvement in friction by $\mathrm{cw}$ Nd:YAG laser surface treatment on cast iron cylinder bore, Appl.Surf. Sci, 205, (2003), 289-296.

9 Abboud J H, Benyounis K Y, Olabi A G, Hashmi M S J, Laser surface treatments of iron-based substrates for automotive application, J. of Mat. Proc. Tech, 182, (2007), 427-431.

10 Xin T, Hong Z, Li Z C, Zhi-hui, Lu-quan R, Effects of $C$ content on the thermal fatigue resistance of cast iron with biomimetic non-smooth surface, Int. J. of Fatigue, 30, (2008), 1125-1133.

11 Knoll G, Lagemann V, Lechtape-Grüter R, Robota A, Schlerege $\mathbf{F}$, Beeinflussung des Ölverbrauchs von Verbrennungsmotoren durch die Mikrohydrodynamik strukturierter Zylinderobeflachen, VDI-Berichte, 1764, (2003), 63-72.

12 Byrnes L, Kramer M, Flores G, HVOF-Coating of Cylinder Bores, VDIBerichte, 1764, (2003), 97-110.

13 Gérard B, Application of thermal spraying in the automobile industry, Surf. and Coat. Tech, 201, (2006), 2028-2031.

14 Bobzin K, Ernst F, Richardt K, Schlaefer T, Verpoort C, Flores G, Thermal spraying of cylinder bores with the plasma transferred wire arc process, Surf. and Coat. Tech, 202, (2008), 4438-4443.

15 Andersson P, Koskinen J, Varjus S, Gerbig Y, Haefke H, Georgiou S, Zhmud B, Buss W, Microlubrication effect by laser-textured steel surfaces, Wear, 262, (2007), 369-379.

16 Herbst L, Lindner H, Heglin M, Hoult T, Targeting diesel engine efficiency, WwW. coherent.com/Downloads/dieselengine_ilsRev2.pdf, 2004

17 Májlinger K, Szabó P J, Measuring the effects of some laser parameters on the surface and near surface region of laser treated cast iron cylinder bore, Per. Pol. Mech. Eng, 52, (2008), 71-76.

18 Májlinger K, Szabó P J, The effects of some laser parameters on the surface and near surface region of laser treated cast iron cylinder bore, J. of Phys. Conf. Ser, 240, (2010), 1-4.

19 Májlinger K, Szabó P J, Laser treatment of cast iron engine cylinder bore with nanosecond laser pulses, Mat. Sci. Forum, 659, (2010), 319-324.

20 Radzikowska $\mathbf{J} \mathbf{M}$, Effect of specimen preparation on evaluation of cast iron microstructures, Mat. Char., 54, (2005), 287-304.

21 Kwong W Y, Zhang W Y, Electron-beam assisted platinum deposition as a protective layer for FIB and TEM applications, in: Semic, Manuf, 21, (2005), 469-471.

22 Munroe $\mathbf{P}$, The application of focused ion beam microscopy in the material sciences, Mat.Char, 60, (2009), 2-13. 